\title{
Ocorrência de Mollicutes e Ureaplasma spp. em surto de doença reprodutiva em rebanho bovino no Estado da Paraíba ${ }^{1}$
}

\author{
Sandra B. dos Santos ${ }^{2 *}$, José W. Pinheiro Júnior ${ }^{3}$, Andréa A.F. Oliveira ${ }^{2}$, André da R. Mota², Júnior \\ Mário Baltazar de Oliveira ${ }^{3}$, Guilherme A. Veras ${ }^{4}$, Elmiro R. do Nascimento ${ }^{5}$ e Rinaldo A. Mota ${ }^{2}$
}

\begin{abstract}
Santos S.B., Pinheiro Júnior J.W., Oliveira A.A.F., Mota A.R., Oliveira J.M.B., Veras G.A., Nascimento E.R. \& Mota R.A. 2013. [Occurrence of Mollicutes and Ureaplasma spp. in outbreak of reproductive disease in cattle herds, State of Paraíba, Brazil.] Ocorrência de Mollicutes e Ureaplasma spp. em surto de doença reprodutiva em rebanhos bovinos no Estado da Paraíba. Pesquisa Veterinária Brasileira 33(3):315-318. Laboratório de Bacterioses dos Animais Domésticos, Departamento de Medicina Veterinária, Universidade Federal Rural de Pernambuco, Av. Dom Manoel de Medeiros s/n, Recife, PE 52171-900, Brazil. E-mail: sanbsantos@gmail.com

In March of 2012 was investigated a reproductive disease outbreak in cattle herds from Paraíba State, Brazil. Were examined 32 cows and two bulls Giroland breed. The cows showed signs and symptoms of reproductive failure such as repeat breeding, granular vulvovaginitis, infertility and abortions. Vaginal and preputial mucous samples were collected for analysis by PCR and isolation. The PCR reactions for Mollicutes and Ureaplasma spp. were realized with primers MGSO and GPO3, and UGP'F and UGP'R respectively. The nested PCR assay for Ureaplasma diversum was realized with primers UD1, UD2, UD3 and UD4. For bacteriologic isolation, obtained samples were diluted up to $10^{-1}$ at $10^{-5}$, inoculated into liquid and solid "UB" medium, and incubated for up to 21 days, at $37^{\circ} \mathrm{C}$ in microaerophilie jar. In the PCR reactions the frequency of Mollicutes detected in the analyzed vaginal mucous samples was 65.6 , for Ureaplasma spp. was 50.0 , while for $U$. diversum was 15.6. The frequency for isolation of Mollicutes was of 57.1 and for Ureaplasma spp. was of 28.6. In the UB agar was visualized growth of Mycoplasma spp. and Ureaplasma spp., associated in six of the samples. In the cows the presence of Mollicutes and Ureaplasma spp. was confirmed for the reproductive disease outbreak in the semiarid region of Paraiba.
\end{abstract}

INDEXS TERMS: Reproductive disease, cattle herds, mycoplasmosis, Mycoplasma spp., Ureaplasma diversum.

RESUMO.- Em março de 2012 foi diagnosticado um surto de doença reprodutiva em rebanho bovino no Estado da Paraíba, Brasil. Foram examinadas 32 vacas e dois touros da raça Girolando. As vacas apresentaram sinais de doença

\footnotetext{
${ }^{1}$ Recebido em 13 de dezembro de 2012.

Aceito para publicação em 28 de janeiro de 2013

${ }^{2}$ Departamento de Medicina Veterinária, Universidade Federal Ru $\neg$ ral de Pernambuco (FRPE), Campus Dois Irmãos, Rua Dom Manoel de Medeiros s/n, Recife, PE 52171-900, Brasil. *Autor para correspondência: sanbsantos@gmail.com

${ }^{3}$ Unidade Acadêmica de Garanhuns, UFRPE, Av. Bom Pastor s/n, Boa Vista, Garanhuns, PE 55292-270, Brasil.

${ }^{4}$ Médico Veterinário autônomo, Rua Quitéria Medeiros 221, Santo Antônio, Garanhuns, PE 55293-420.

${ }^{5}$ Departamento de Saúde Coletiva Veterinária e Saúde Pública, Faculdade de Medicina Veterinária, Universidade Federal Fluminense (UFF), Rua Vital Brasil 64, Santa Rosa, Niterói, RJ 24020-150, Brasil.
}

reprodutiva como repetição de cio, vulvovaginite granular, infertilidade e abortos. As amostras de suabes vaginais e prepuciais foram colhidas e submetidas a isolamento bacteriano e PCR. As reações da PCR para Mollicutes e Ureaplasma spp. foram realizadas com os iniciadores MGSO-GPO3 e UGP'F-UGP'R, respectivamente. Na Nested PCR para Ureaplasma diversum, os iniciadores usados foram UD1, UD2, UD3 e UD4. Para isolamento bacteriano, as amostras foram diluídas de $10^{-1}$ até $10^{-5}$, semeadas em meio "UB", líquido e placa, sendo incubadas por até 21 dias a $37^{\circ} \mathrm{C}$ em jarra de microaerofilia. A frequência de Mollicutes detectada na PCR foi de $65,6 \%$ e para Ureaplasma spp. foi de 50,0\%, enquanto que para $U$. diversum foi de $15,6 \%$. No isolamento a frequência de Mollicutes foi de 57,1\% e para Ureaplasma spp. foi de $28,6 \%$. No ágar "UB" foi visualizado o crescimento misto de Mycoplasma spp. e Ureaplasma spp. em seis amos- 
tras. Foi confirmado o envolvimento de micro-organismos da Classe Mollicutes em surto de doença reprodutiva em vacas no sertão paraibano.

TERMOS DE INDEXAÇÃO: Doença reprodutiva, bovinos, Мycoplasma spp., Ureaplasma diversum, micoplasmose.

\section{INTRODUÇÃO}

De acordo com Buzinhani et al. (2007), as infecções por micro-organismos da classe Mollicutes em animais possuem importância histórica e persistem interferindo na pecuária. São relatadas na literatura aproximadamente 200 espécies de Mollicutes, mas destas apenas algumas são consideradas patogênicas para os animais de produção, principalmente os micoplasmas (Frey 2002). Em bovinos destacam-se Mycoplasma mycoides subsp. mycoides SC e Mycoplasma bovis, sendo esta última responsável por quadros de artrite, meningite, distúrbios reprodutivos e forma grave de mastite. Ureaplasma diversum também assume importância por causar distúrbios reprodutivos (Marques 2009).

Ureaplasma diversum foi considerado comensal por muito tempo, mas atualmente tem importância veterinária reconhecida, pois já foi identificada em alguns casos de distúrbios reprodutivos em ruminantes. Essa bactéria é isolada com frequência em vacas com histórico de aborto (Maxie 1986) e em lesões da vulva (Mulira et al. 1992). Cardoso et al. (1997) fizeram o primeiro relato da identificação de $U$. diversum no muco vaginal de vacas com Vulvovaginite Granular no Brasil. Em 2000a, Cardoso et al. também isolaram $U$. diversum em $35,7 \%$ de 168 amostras de muco vulvovaginal de vacas. A presença desse agente em fetos abortados, placenta e conteúdo estomacal também têm sido descrita na literatura (Landford 1975, Ruhnke et al. 1984, Trichard \& Jacobz 1985). U. diversum já foi isolada de surtos de vulvovaginite granular, seguidos de abortamento e redução da eficiência reprodutiva (Nascimento et al. 1998, Cardoso et al. 2000a, 2006, Cardoso \& Vasconcelos 2004, Nascimento et al. 2005, Oliveira Filho et al. 2005).

No Brasil, esta bactéria foi identificada no muco vaginal de vacas leiteiras com histórico de repetição de estro no Estado de Alagoas (Oliveira Filho et al. 2005). Os autores relataram que o isolamento do agente esteve associado à presença de lesões na mucosa vulvovaginal e concluíram que $U$. diversum deve ser considerado como agente responsável por queda na eficiência reprodutiva e retorno ao estro provavelmente em consequência de mortalidade embrionária. Buzinhani et al. (2007) também isolaram Mycoplasma spp. e Ureaplasma spp. no muco vulvovaginal de vacas com histórico de distúrbios reprodutivos (vulvite granular, infertilidade e aborto) em propriedades dos estados de São Paulo, Goiás e Santa Catarina.

Ainda no Brasil foram relatados outros surtos de abortos associados ao isolamento de $U$. diversum, destacando-se os trabalhos realizados por Buzinhani et al. (2007) que isolaram Mycoplasma spp. e U. diversum em 12,5\% e 25,0\% no muco vaginal em vacas com distúrbios reprodutivos. Em touros, Vianna et al. (2004) identificaram Ureaplasma diversum por meio da PCR em amostras de sêmen, resultando em infertilidade dos touros estudados.
De acordo com Huffman et al. (1985) e Miller et al. (1994), os fatores mais importantes que desencadeiam perdas econômicas por micoplasmas e ureaplasmas em propriedades agropecuárias são a diminuição do número de gestações, ocorrência de perdas fetais ou partos prematuros com consequente diminuição do número de serviços por animal, perdas na qualidade do sêmen e aumento dos custos com veterinários e drogas para tratamento das infecções.

Considerando-se as escassas informações sobre a ocorrência de infecção por bactérias da classe Mollicutes em distúrbios reprodutivos em bovinos na região Nordeste do Brasil, relata-se a ocorrência de um surto de doença reprodutiva (abortos e vulvovaginite granular) em bovinos de aptidão leiteira no município de Souza, PB.

\section{MATERIAL E MÉTODOS}

\section{Histórico do rebanho}

No mês de março de 2012 foi visitada uma propriedade cujo rebanho era composto de 200 animais da raça Girolando, sendo 114 vacas, das quais 94 em lactação, com produção média de 1. 500 litros/dia. Os animais eram criados em regime semi-intensivo, recebiam suplementação mineral, a fonte de água era corrente e a alimentação à base de capim suplementado com ração, casca de mandioca, silagem, milho, caroço de algodão e suplementação mineral. Os animais eram vacinados para IBR, BVD, Leptospirose, Raiva, Brucelose e Febre Aftosa. Os animais de reposição eram adquiridos de outras propriedades e a fazenda não realiza quarentena. 0 manejo reprodutivo empregado na propriedade incluía monta natural e inseminação artificial com sêmen atestado sanitariamente. Os animais com sinais reprodutivos crônicos eram encaminhados para o abate.

\section{Coleta das amostras}

Foram coletadas amostras de dois touros sem sinal de doença reprodutiva e 32 vacas com sinais clínicos de distúrbios reprodutivos como repetição de cio, vulvovaginite granular, infertilidade e aborto aos três meses e no terço final da gestação. As amostras de muco vaginal foram coletadas ao término da ordenha, sendo feita higienização prévia da região vulvar externa com toalha de papel e álcool a 70\%. A colheita foi feita a partir da fricção do suabe na parede interna da mucosa vaginal e prepucial. Os suabes foram armazenados em tubos falcon estéreis contendo 3mL de solução salina tamponada estéril (PBS pH 7,2). As amostras de muco prepucial foram coletadas após a realização da tricotomia, lavagem e antissepsia do prepúcio. Todas as amostras foram mantidas sob refrigeração até o processamento no Laboratório de Doenças Infectocontagiosas da UFRPE.

\section{Diagnóstico molecular e isolamento bacteriano}

As amostras de suabes vaginal e prepucial foram aliquotadas em volume de $1 \mathrm{~mL}$ e devidamente armazenadas para a extração do DNA genômico. Para a extração de DNA foi utilizado o kit comercial "Qiagen DNA Easy Blood and Tissues Kit" (Qiagen $®)$, de acordo com o protocolo do fabricante. A PCR para Mollicutes foi realizada com os oligonucleotídeos MGSO (5'-TGC ACCATCTGTCACTCTGTTAACCTC-3') e GPO3 (5'- GGG AGC AAA CAG GAT TAG ATA CCC T - 3') com perfil térmico previamente descrito (Kuppeveld et al. 1992). A reação consistiu de um mix com volume final de $25 \mu \mathrm{L}$, contendo $10 \mathrm{mM}$ de Tris- $\mathrm{HCl}, \mathrm{pH} 8,3 ; 25 \mathrm{mM}$ de $\mathrm{MgCl}_{2}$; $50 \mu \mathrm{M}$ de dNTPmix; 2,5U de Taq DNA polimerase; $30 \mathrm{pmol}$ de cada primer; $5 \mu \mathrm{L}$ de DNA genômico e água ultrapura para PCR. Como 
controle positivo da reação foi utilizado a cepa Mycoplasma mycoides mycoides (GM12, ATCC) e o controle negativo foi água de PCR. Para detecção do gênero Ureaplasma spp. foi realizada PCR com os oligonucleotídeos UGPF (5' - GGA TGA GGG TGC GAC GTA TC - 3’) e UGPR (5'- GCG TTA GCT ACA ACA CCG AC - 3'), com perfil térmico descrito por Lauerman (1998). A reação consistiu de um mix contendo $5 \mu \mathrm{L}$ de DNA genômico, 30pmol de cada iniciador (UGP-F' e UGP-R'), 6,25 $\mu \mathrm{L}$ de TopTaq Mastermix e água Mili-Q ultrapura. A nested PCR para $U$. diversum foi realizada com os iniciadores UD1 (5'-CCG GAT AAT AAC ATT TAC TT-3'), UD2 (5'-TCG ATA CTG CTA CCG CAA GG-3'), UD3 (5'-AAT GTC GGC TCG CTT ATG AG-3') e UD4 (5'-GCG GAG GTT AAC AAT ATG ACA CG-3'), com perfil térmico baseado em Cardoso et al. (2000b). Os reagentes foram utilizados nas seguintes concentrações $10 \mathrm{mM}$ de Tris- $\mathrm{HCl}, \mathrm{pH}$ 8,3; $25 \mathrm{mM}$ de $\mathrm{MgCl}_{2} ; 50 \mu \mathrm{M}$ de dNTPmix; 2,5U de Taq DNA polimerase; 30pmol de cada iniciador; $5 \mu \mathrm{L}$ de DNA genômico e água ultrapura para PCR. Na reação da nested PCR foram utilizados os iniciadores UD3 e UD4 (10pmol), repetindo-se as concentrações dos reagentes e o perfil térmico da primeira reação. 0 controle positivo nas reações para Ureaplasma spp. e U. diversum foi a cepa ATCC (GMU132).

Para o isolamento as amostras de suabes vaginal e prepucial foram filtradas em Holder com membrana milipore $(0,45 \mu \mathrm{m})$ estéril. As amostras foram diluídas de $10^{-1}$ até $10^{-5}$ e a última diluição foi semeada em meio "UB", caldo e placa, de acordo com Whitford et al. (1994) e Razin \& Tully (1995). Todas as placas e caldos foram incubados a $37^{\circ} \mathrm{C}$ em microaerofilia por até 21 dias, sendo as placas examinadas em microscópio estereoscópio (80x). Os cultivos em caldo foram identificados com base nas propriedades metabólicas e as colônias suspeitas foram submetidas à coloração de Dienes e prova de urease (Razin \& Tully 1996).

\section{RESULTADOS}

Das 32 vacas examinadas, 90,6\% (29/32) apresentaram histórico de repetição de cio e 12,5\% (4/32) histórico de aborto recente, sendo 75,0\% no terço final da gestação e $25,0 \%$ aos três meses de gestação. Em 18,7\% (6/32) das vacas foram observadas lesões de vulvovaginite granular. A frequência de Mollicutes detectada na PCR foi de $65,6 \%$ (21/32) e para Ureaplasma spp. foi de 50,0\% (16/32), enquanto para $U$. diversum foi de $15,6 \%(5 / 32)$.

Dos animais positivos na PCR para Mollicutes, 59,4\% apresentaram repetição de cio; 6,3\% apresentaram abortos e $15,6 \%$ vulvovaginite granular. Dos animais positivos na PCR para Ureaplasma spp. 46,9\% apresentaram repetição de cio; 3,1\% aborto e 12,5\% vulvovaginite granular. Em $18,8 \%$ dos animais foram observados a presença dos três distúrbios reprodutivos associados.

No isolamento bacteriológico as amostras de suabes reprodutivos semeadas em meio "UB" apresentaram mudança de $\mathrm{pH}$, demonstrando coloração marrom pela presença de ureia no meio. No isolamento foi observado em ágar "UB" o crescimento de Mollicutes em 57,1\% (12/21) e Ureaplasma spp. em $28,6 \%$ (6/21), em seis amostras foi observado o crescimento misto de Mycoplasma spp. e Ureaplasma spp. em meio UB.

\section{DISCUSSÃO E CONCLUSÃO}

A alta frequência detectada para Mollicutes e Ureaplasma spp. na PCR e isolamento em vacas com quadro de doença reprodutiva demonstra o envolvimento destes agentes no surto de doença reprodutiva no sertão paraibano. A fre- quência detectada na PCR para Mollicutes foi aproximada àquela detectada por Buzinhani et al. (2007) que encontraram $69,9 \%$ das amostras positivas utilizando a mesma técnica em suabes de muco vulvovaginal de vacas.

A participação de Mollicutes em doenças da reprodução em bovinos tem sido relatada em alguns estudos realizados em outras regiões do Brasil (Nascimento et al. 1998, Cardoso et al. 2000a, 2006, Cardoso \& Vasconcelos 2004, Nascimento et al. 2005, Oliveira Filho et al. 2005, Buzinhani et al. 2007), sendo as espécies $M$. bovirhinis, M. bovigenitalium, M. bovis, U. diversum e Mycoplasma spp. as mais frequentemente isoladas nos casos de distúrbios reprodutivos. A presença de Mollicutes em muco vulvovaginal de vacas pode ocorrer sem associação com surtos de doença reprodutiva (Petit et al. 2007, Smith et al. 2012), no entanto, quando isolados em muco cervical e/ou sistema reprodutor superior estão relacionados a síndrome reprodutiva caracterizados por repetição de cio, infertilidade, endometrites, abortos, nascimento de bezerros fracos entre outros (Ruhnke et al. 1984, Petit et al. 2007).

Os principais problemas reprodutivos verificados no rebanho estudado foram semelhantes aos encontrados por Cardoso et al. (2000a) e Nascimento et al. (2005), no entanto, não se observou descarga vaginal purulenta, mas sim a presença de hiperemia vaginal e lesões granulomatosas, além do histórico recente de repetições de cio, infertilidade e abortos. Segundo Cardoso et al. (2000a), a descarga vulvar purulenta é frequente nos casos de vulvite granular (VVG) e a hiperemia vulvar ocorre na fase aguda e possui graus variáveis.

$U$. diversum é um dos principais agentes infecciosos envolvidos nos casos de VVG, abortos, repetições de cio e infertilidade de fêmeas, podendo ser transmitido pela monta natural, inseminação artificial e transferência de embriões (Cardoso \& Vasconcelos 2004, Marques et al. 2009). Neste estudo a nested PCR para $U$. diversum detectou uma frequência menor do que a detectada pela PCR convencinal para o gênero Ureaplasma spp., isto pode ter ocorrido devido a perdas de DNA genômico no armazenamento e/ou presença de inibidores na reação, uma vez que a nested PCR para $U$. diversum tem sido referida como uma técnica altamente sensível e específica (Cardoso et al. 2000b, Buzinhani et al. 2007).

A ocorrência de abortos nesta propriedade pode estar associada com a presença de $U$. diversum, uma vez que esta bactéria tem sido encontrada em casos de abortos em bovinos em outras regiões do País, no entanto, a virulência da cepa isolada ainda não foi avaliada para comprovar sua patogenicidade. De acordo com Le Grand et al. (1995), presença de alterações reprodutivas causadas por $U$. diversum estão associadas às variações na virulência entre as cepas.

A presença de $U$. diversum no sistema reprodutivo já foi relatada em vários países em surtos de abortos e o isolamento do agente em fetos abortados, neonatos, placenta e conteúdo estomacal tem sido descrita na literatura (Landford 1975, Ruhnke et al. 1984, Trichard \& Jacobz 1985). No Brasil, surtos de doença reprodutiva em vacas foram associadas às espécies $M$. bovirhinis, $M$. bovigenitalium e U. diversum (Cardoso et al. 1997, 2000a, Nascimento et al. 
1998, Nascimento et al. 2005, Buzinhani et al. 2007). Мycoplasma spp. foi isolado em muco vulvovaginal de vacas por Nascimento et al. (2005), onde a presença do agente foi relacionada com doenças reprodutivas como vulvovaginite, aborto e presença de natimorto. Buzinhani et al. (2007) encontraram frequência de $25,0 \%$ no isolamento de $U$. diversum em muco vaginal de vacas com doença reprodutiva no isolamento. Oliveira Filho et al. (2005) associaram a presença de lesões na mucosa vulvovaginal com a presença de $U$. diversum, tendo encontrado graus de lesões que variaram de 0 a 3, com as frequências relativas variando de $4,1 \%$ a $28,8 \%$.

Neste estudo, as duas amostras de muco prepucial foram negativas para Mollicutes nas técnicas de isolamento e PCR; isto pode ter ocorrido por vários motivos, dentre eles, um baixo número de micro-organismos na amostra colhida e perdas de DNA durante os procedimentos de extração. Cardoso et al. (2006) demonstraram que o muco prepucial é um material biológico que pode ser utilizado para detecção de Mollicutes e Smith et al. (2012) encontraram uma frequência de $35,2 \%$ de suabes do sistema urogenital positivos para $U$. diversum em animais sem lesões reprodutivas.

Os resultados da PCR e isolamento confirmaram a participação de Mollicutes como agentes envolvidos na doença reprodutiva em bovinos no sertão paraibano. Outros estudos devem ser conduzidos com o objetivo de isolar esses agentes em fetos abortados e material placentário para confirmar a real participação destas bactérias em casos de abortos na região nordeste do Brasil.

\section{REFERÊNCIAS}

Buzinhani M., Metiffogo E. \& Timenetsky J. 2007. Detecção de Mycoplasma spp. e Ureaplasma diversum em vacas com distúrbios reprodutivos. Arq. Bras. Med. Vet. Zootec. 59(6):1368-1375.

Cardoso M.V., Grasso L., Stefano E., Okuda L.H. \& Cunha R.A.F. 1997. Isolamento de Ureaplasma diversum e Mycoplasma spp. em casos de Vulvite Granular Bovina. Revta Bras. Reprod. Anim. 21(2):172-173.

Cardoso M.V., Scarcelli E., Grasso L.M.P.S., Teixeira S.R. \& Genovez M.E. 2000a. Ureaplasma diversum and reproductive disorder in Brazilian cows and heifers, first report. Anim. Reprod. Sci. 63:137-143.

Cardoso M.V., Blanchard A., Ferris S., Verlengia R., Timenetsky J. \& Da Cunha R.A.F. 2000b. Detection of Ureaplasma diversum in cattle using a newly developed PCR-based detection assay. Vet. Microbiol. 72(3/4): 241-250.

Cardoso M.V. \& Vasconcelos S.A. 2004. Importância das micoplasmoses na infertilidade de touros. Arqs Inst. Biológico, São Paulo, 71(2):257-265.

Cardoso M.V., Teixeira S.R., Miyashiro S., Vasconcellos S.A., Gregory L. \& Genovez M.E. 2006. Estudo comparativo entre técnicas de isolamento e PCR para detecção de Mycoplasma e Ureaplasma diversum em muco prepucial e sêmen in natura de touros de monta natural e central de inseminação artificial. Arqs Inst. Biológico, São Paulo, 73(1):33-40.

Frey J. 2002. Mycoplasmas of animals, p.73-90. In: Razin S. \& Herrmann R. (Eds), Molecular Biology and Pathogenicity of Mycoplasmas. Kluwer Academic, New York.

Huffman E.M., Christensen V., Hird D. \& Jasper D. 1985. Epidemiology of bovine genital ureaplasma infection. Proc. Soc. Theriol., p.67-7l.
Kuppeveld V.F.J.M., Logt J.T.M., Angulo A.F., Zoest M.J., Quint W.G.V., Niesters H.G.M., Galama J.M.D. \& Melchers W.J.G. 1992. Genus- and species-specific identification of Mycoplasmas by 16 rRNA amplification. Appl. Environ. Microbiol. 58:2606-2615.

Lauerman L.H. 1998. Mycoplasma PCR assays, p.41-42. In: Lauerman L.H. (Ed.), Nucleic Acid Amplification Assays for Diagnosis of Animal Diseases. American Association of Veterinary Laboratory Diagnosticians, Turlock, CA

Landford E.V. 1975. Mycoplasma species recovered from the reproductive tracts of Western Canadian cows. Can. J. Comp. Med. 39:133-137.

Le Grand D., Poumarat F. \& Marrel J.L. 1995. Infection génitale à Ureaplasma diversum: enquête chez les bovins en France. Vet. Res. 26:11-20.

Marques L.M. 2009. Estudo da variabilidade genética e dos fatores de virulência de isolados de Ureaplasma diversum. Tese de Doutorado, Universidade de São Paulo, São Paulo, SP. 102p.

Marques L.M., Buzinhani M., Neto R.L., Oliveira R.C., Yamaguti M., Guimarães A.M. \& Timenetsky J. 2009. Detection of Ureaplasma diversum in bovine semen straws for artificial insemination. Vet. Rec. 165:572-573. doi: 10.1136/vr.165.19.572.

Maxie M.G. 1986. Etiologic agent or condition associated with abortion in cattle: VLS, Guelph, 1983-1985. Can. Vet. J. 27:A6.

Miller R.B., Chelmonska-Soyta A., Srnits B., Foster R. \& Rosendal S. 1994. U. diversum as a cause of reprodutive disease in cattle. Vet. Clin. North Am., Food Am. Pract. 10:479-490.

Mulira G.L., Saunders R.J. \& Barth D.A. 1992. Isolation of Ureaplasma diversum and mycoplasma from genital tracts of beef and dairy cattle in Saskatchewan. Can. Vet. J. 33:46-49.

Nascimento M.G.F., D'Angelis F.H.F., Nascimento E.R., Resende O.A. \& Lignon G.B. 1998. Mycoplasma bovirhinis em muco vaginal de novilhas. Revta Bras. Med. Vet. 20(5):210-214.

Nascimento M.G.F., D`angelis F.H.F., Nascimento E.R. \& Resende O.A. 2005. Envolvimento de micoplasmas em vacas com distúrbios reprodutivos. Acta Scientiae Veterinária. 33(2):195-199.

Oliveira Filho B.D., Porto R.N.G., Gambarini M.L., Kunz T.L., Ferraz H.T., Viu M.A.O., Lopes D.T. \& Sousa A.P.F. 2005. Isolamento do Ureaplasma diversum em muco vulvovaginal de vacas leiteiras repetidoras de estro no Estado de Alagoas, Brasil. Archs Vet. Sci. 10(2):151-156.

Petit T., Spergser J., Aurich J. \& Rosengarten R. 2007. Prevalence of Chlamydiaceae and Mollicutes on the genital mucosa and serological findings in dairy cattle. Vet. Microbiol. Doi:10.1016/j.vetmic.2007.08.022.

Razin S. \& Tully J.G. 1995. Molecular and Diagnostic Procedures in Mycoplasmology. Vol.1. Academic Press, California, 481p.

Razin S. \& Tully J.G. 1996. Molecular and Diagnostic Procedures in Mycoplasmology. Vol.2, Academic Press, California. 463p.

Ruhnke H.L., Palmer N.C., Doig P.A. \& Miller R.B. 1984. Bovine abortion and neonatal death associated with Ureaplasma diversum. Theriogenology 21(2):295-301.

Smith A., Chousalkar K.K. \& Chenoweth P.C. 2012. Polymerase chain reaction for detection of Ureaplasma diversum from urogenital swabs in cattle in Australia. Australian Veterinary Journal 90(7):275-276.

Trichard C.J.V. \& Jacobsz E.P. 1985. Mycoplasmas recovered from bovine genitalia, aborted foetuses and placentas in the Republic of South Africa. Onderstepoort J. Vet. Res. 52:105-110.

Vianna F.P., Cardoso M.V., Scarcelli E., Campos F.R., Teixeira S.R. \& Miyashiro S. 2004. Relato de infertilidade de touros da raça nelore relacionada à presença de Ureaplasma diversum e Histophilus somni. Arqs Inst. Biológico, São Paulo, 71:1-749.

Whitford H.W., Rosenbusch R.F. \& Lauerman L.H. 1994. Mycoplasmosis in Animals: laboratory diagnosis. lowa State University Press, Ames. 173p. 